Débora Miriam Raab Glina 1

\title{
Saúde mental e trabalho: uma reflexão sobre o nexo com o trabalho e o diagnóstico, com base na prática
}

\author{
Mental health and work: \\ a discussion of the connection between work \\ and diagnosis based on daily practice
}

Lys Esther Rocha 2

Maria Lucia Batista 3

Maria Goretti Vieira Mendonça 3

\footnotetext{
1 Departamento de Saúde Ambiental, Faculdade de Saúde Pública, Universidade de São Paulo. Av. Dr. Arnaldo 715 sala 217, São Paulo, SP 01246-904, Brasil. deboraglina@originet.com.br 2 Departamento de Medicina Legal, Ética Médica, Medicina Social e do Trabalho, Faculdade de Medicina LIM-40 Universidade de São Paulo. Rua Teodoro Sampaio 115. São Paulo, SP 05405-000, Brasil. lysrocha@usp.br

3 Centro de Referência de Saúde do Trabalhador André Gabois, Secretaria Municipal da Saúde, Prefeitura Municipal de São Paulo. Rua Frederico Alvarenga 259, 5o andar, São Paulo, SP 01020-030, Brasil.
}

\begin{abstract}
Seven cases of workers selected among 150 who had undergone psychiatric treatment at the Workers' Health Reference Centers in Santo Amaro and André Gabois from 1994 to 1997 were presented for a detailed analysis characterizing work situations and discussing definition of the diagnosis and causal connections with work. The qualitative case study provides a thematic analysis of the patient history and files. Work situations are characterized by: unhealthy working conditions, problems related to work organization, inadequate human resources management, and urban violence. Symptoms included: fear, anxiety, depression, nervousness, tension, fatigue, malaise, loss of appetite, sleep disorders, and psychosomatic disorders (gastritis, hypertension); in addition, workers were unable to forget about work while off the job. Diagnosis varied. Three cases involved post-traumatic syndrome. Two cases involved organic psychosis linked to accidents or exposure to neurotoxic chemical products. Cases also included neurotic syndromes of fatigue, depression, and paranoia, as well as adaptation and reaction to acute stress. In all of the cases it was possible to relate the clinical picture to the work situation.
\end{abstract}

Key words Stress; Occupational Health; Mental Health

Resumo São apresentados sete casos de saúde mental, dentre os 150 atendidos nos Centros de Referência em Saúde do Trabalhador de Santo Amaro e André Gabois, no período de 1994 a 1997. Com base na análise das anamneses e prontuários, buscou-se caracterizar as situações de trabalho, discutir o estabelecimento do diagnóstico e do nexo causal com o trabalho. As situações de trabalho caracterizaram-se por: condições de trabalho nocivas, problemas relacionados à organização do trabalho, gestão inadequada de pessoal e violência. Os quadros clínicos mostraram a existência de medo, ansiedade, depressão, nervosismo, tensão, fadiga, mal-estar, perda de apetite, distúrbios de sono, distúrbios psicossomáticos (gastrite, crises hipertensivas), além disso, ocorreu contaminação involuntária do tempo de lazer, ou seja, os trabalhadores sonhavam com o trabalho, não conseguiam "desligar-se". Os diagnósticos foram variados. Em três casos tivemos síndromes pós-traumáticas ligadas a assaltos. Dois casos referem-se a quadros psicóticos orgânicos ligados a acidentes ou exposição a produtos químicos. Apareceram ainda síndromes neuróticas de fadiga, depressivas, paranóides, de adaptação e de reação ao estresse grave. Em todos os casos foi possível relacionar o quadro clínico com a situação de trabalho.

Palavras-chave Estresse; Saúde Ocupacional; Saúde Mental 


\section{Introdução}

Embora apresentem alta prevalência entre a população trabalhadora, os distúrbios psíquicos relacionados ao trabalho freqüentemente deixam de ser reconhecidos como tais no momento da avaliação clínica. Contribuem para tal fato, entre outros motivos, as próprias características dos distúrbios psíquicos, regularmente mascarados por sintomas físicos, bem como a complexidade inerente à tarefa de definir-se claramente a associação entre tais distúrbios e o trabalho desenvolvido pelo paciente.

Dentre os modelos de explicação das relações entre saúde mental e trabalho podemos definir duas principais correntes: a psicopatologia do trabalho - denominada psicodinâmica do trabalho a partir dos estudos efetuados por Dejours - e os estudos que tratam da relação entre estresse e trabalho.

A psicodinâmica do trabalho enfatiza a centralidade do trabalho na vida dos trabalhadores, analisando os aspectos dessa atividade que podem favorecer a saúde ou a doença. Ao analisar a inter-relação entre saúde mental e trabalho, Dejours (1986) acentua o papel da organização do trabalho no que tange aos efeitos negativos ou positivos que aquela possa exercer sobre o funcionamento psíquico e à vida mental do trabalhador. Este autor conceitua organização do trabalho como a divisão das tarefas e a divisão dos homens. A divisão das tarefas engloba o conteúdo das tarefas, o modo operatório e tudo que é prescrito pela organização do trabalho. A divisão dos homens compreende a forma pela qual as pessoas são divididas em uma empresa e as relações humanas que aí se estabelecem.

Mais recentemente, Dejours et al. (1994) passaram a acentuar o fato de que a relação entre a organização do trabalho e o ser humano encontra-se em constante movimento. Do ponto de vista da Ergonomia, a análise da organização do trabalho deve levar em conta: a organização do trabalho prescrita (formalizada pela empresa) e a organização do trabalho real (o modo operatório dos trabalhadores). Segundo Dejours, o descompasso entre as duas favoreceria o aparecimento do sofrimento mental, uma vez que levaria o trabalhador à necessidade de transgredir para poder executar a tarefa.

Conforme apontamos antes, a segunda corrente de análise dedicada à inter-relação saúde mental e trabalho é a que privilegia a relação entre estresse e trabalho. Tal abordagem apresenta um alto grau de complexidade, a começar por uma ampla variação do conceito de estresse. Destacam-se, nesse campo, os autores escandinavos (Frankenhaeuser \& Gardell, 1976; Kalimo, 1980; Levi, 1988), que definem estresse como um desequilíbrio entre as demandas do trabalho e a capacidade de resposta dos trabalhadores.

No âmbito desta vertente, observa-se a preocupação com a determinação dos fatores potencialmente estressantes em uma situação de trabalho. Karasek \& Theorell (1990) propõem um modelo com uma abordagem tridimensional, contemplando os seguintes aspectos: "exigência/controle" (demand/control); "tensão/ aprendizagem” (strain/learning) e suporte social. A situação saudável de trabalho seria a que permitisse o desenvolvimento do indivíduo, alternando exigências e períodos de repouso com o controle do trabalhador sobre o processo de trabalho.

No Brasil, Seligmann-Silva (1994) identifica a existência de um campo de estudo interdisciplinar voltado para a análise das conexões entre saúde mental e trabalho, mediante a integração de "olhares" distintos, apresentando o conceito de desgaste como opção conceitual integradora. O desgaste psíquico foi associado à imagem de "mente consumida" por Seligmann-Silva reunindo três abrangências: a primeira, compreendendo quadros clínicos relacionados ao desgaste orgânico da mente (seja em acidentes do trabalho, seja pela ação de produtos tóxicos); a segunda, compreendendo as variações do "mal-estar", das quais a fadiga (mental e física) é uma das analisadas; e a terceira, quando se verificam os desgastes que afetam a identidade do trabalhador, ao atingir valores e crenças, que podem ferir a dignidade e a esperança.

Em resumo, o espectro da inter-relação saúde mental e trabalho abrange, portanto, do malestar ao quadro psiquiátrico, incluindo o sofrimento mental. Para Dejours et al. (1994) o sofrimento mental, pode ser concebido como a experiência subjetiva intermediária entre doença mental descompensada e o conforto (ou bem-estar) psíquico. A não-caracterização do papel do trabalho como agravante ou desencadeante de distúrbios psíquicos ocasiona prejuízos não só à qualidade e à eficácia do tratamento, como aos direitos legais do trabalhador, que deixa de usufruir de benefícios previdenciários aos quais eventualmente tenha direito.

O Centro de Referência de Saúde do Trabalhador de Santo Amaro (CRST-SA) foi criado em 1990 e o de André Gabois (CRST-SÉ) foi criado em 1992, com a finalidade de atender respectivamente os trabalhadores da região sul e da região central do Município de São Paulo. Tendo como objetivo, entre outros, desvelar a ocor- 
rência de doenças profissionais, dos acidentes do trabalho e de doenças relacionadas ao trabalho, entre elas as doenças/sofrimentos mentais. Na prática, porém, os distúrbios psíquicos relacionados ao trabalho têm representado pequena parcela do atendimento dos Centros de Referência (Daúd Jr., 1997). Isso ocorre dadas as dificuldades inerentes ao reconhecimento da inter-relação saúde e trabalho por parte dos profissionais dos serviços de saúde, dos sindicatos e dos próprios trabalhadores.

O Decreto 3.048/99 de 06 de maio de 1999 do Ministério da Previdência e Assistência Social (MPAS, 1999), apresenta na Lista B do Regulamento da Previdência a nova Lista de Doenças Profissionais e Relacionadas ao Trabalho. Fazem parte desta lista um conjunto de doze categorias diagnósticas de transtornos mentais. Esse decreto representa um avanço, mas traz um desafio: reconhecer, diagnosticar e fazer o nexo causal dos transtornos mentais com o trabalho.

Neste estudo são apresentados casos de saúde mental atendidos nos Centros de Referência em Saúde do Trabalhador de Santo Amaro e André Gabois, com o objetivo de caracterizar as situações de trabalho relacionadas aos distúrbios psíquicos apresentados pelos pacientes e discutir a questão do estabelecimento do diagnóstico e do nexo causal com o trabalho, contribuindo assim para a prática dos profissionais de saúde.

\section{Metodologia}

Foram selecionados sete casos dentre os 150 atendimentos de distúrbios psíquicos relacionados ao trabalho e trabalhadores portadores de LER/DORT (Lesões por Esforços Repetitivos/Distúrbios Osteomusculares Relacionados ao Trabalho) nos dois CRSTs, no período de 1994 a 1997, para uma análise detalhada dos casos. Tais pacientes haviam sido encaminhados pelos médicos do trabalho do próprio serviço e pelos sindicatos, com vistas à elaboração de relatórios destinados à Previdência Social. Estes casos foram selecionados devido à sua diversidade, representando dados pessoais, situações de trabalho e diagnósticos diferenciados, o que permite uma visão mais abrangente das situações de trabalho relacionadas aos distúrbios psíquicos (Tabela 1). Não houve intenção de realizar um estudo epidemiológico com amostra representativa de atendimentos de saúde mental nos dois centros de referência.

Trata-se de estudo qualitativo de casos, não representativo estatisticamente, mas cuja significação é alcançada pela diversificação das situações vivenciadas pelos trabalhadores e da escolha de categorias que permitem uma aproximação do fenômeno estudado (Minayo, 1993). Segundo Minayo (1993), em pesquisas qualitativas existe uma preocupação menor com a generalização e maior com o aprofundamento e abrangência da compreensão seja de um grupo social, de uma organização, de uma política ou de uma representação, motivo pelo qual o critério de amostragem não é numérico: “(...) uma amostragem qualitativa: a) privilegia os sujeitos sociais que detêm os atributos que o investigador pretende conhecer; $b$ ) considera-os em número suficiente para permitir uma reincidência das informações, porém não despreza informações ímpares cujo potencial explicativo tem que ser levado em conta; c) entende que na homogeneidade fundamental relativa aos atributos, o conjunto de informantes possa ser diversificado para possibilitar a apreensão de semelhanças e diferenças; d) esforça-se para que a escolha do locus e do grupo de observação e informantes contenham o conjunto das experiên-

Tabela 1

Casos apresentados em relação ao sexo, estado civil, escolaridade, idade, naturalidade, ramo de atividade econômica e último cargo.

\begin{tabular}{|c|c|c|c|c|c|c|c|}
\hline Caso & Sexo & Estado civil & Escolaridade & Idade em anos & Naturalidade & Ramo de atividade & Último cargo \\
\hline 1 & M & Casado & 1으 Gl & 46 & SP & Transporte coletivo & Motorista \\
\hline 2 & M & Casado & $1 \mathrm{GC}$ & 41 & BA & Indústria de vidros & Encarregado de linha \\
\hline 3 & M & Solteiro & $1 \circ \mathrm{GC}$ & 39 & SP & Serviço de saúde pública & Dedetizador \\
\hline 4 & $\mathrm{~F}$ & Separada & 2으 GI & 39 & $A L$ & Transporte coletivo & Agente de segurança \\
\hline 5 & M & Casado & $2 \circ \mathrm{GC}$ & 34 & SP & Banco & Caixa \\
\hline 6 & M & Separado & 1 으C & 37 & MG & Transporte coletivo & Motorista \\
\hline 7 & M & Casado & $\mathrm{SI}$ & 43 & SP & Banco & Gerente de produção \\
\hline
\end{tabular}

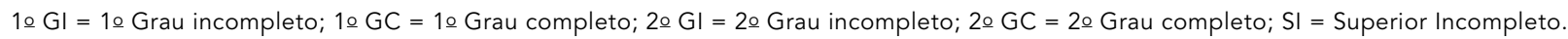


cias e expressões que se pretende objetivar com a pesquisa" (Minayo, 1993:102).

Realizados por equipe multidisciplinar constituída por psiquiatra, psicóloga e, no caso do CRST-SÉ, também por assistente social, os atendimentos de Saúde Mental pautaram-se pela adoção de uma perspectiva holística e pela análise acurada da situação de trabalho do paciente, buscando a compreensão da inter-relação entre trabalho e vida fora do trabalho na determinação da saúde psíquica e também pelo conceito de integração entre o corpo e a mente, isto é, entre sofrimento físico e psíquico do trabalhador.

Podemos considerar a anamnese uma entrevista semi-estruturada, cujo roteiro foi seguido com certa flexibilidade. O roteiro abrangeu coleta detalhada da história de vida, história clínica, história ocupacional, condições de vida, dados sobre o próprio trabalho e a situação atual de trabalho. Com relação à história clínica, além da queixa livre, foi utilizada uma checklist de sintomas. Verificou-se ainda a existência de consumo de drogas. Em relação às condições de vida abrangeu-se: família, convívio atual, moradia, alimentação, trajeto. A descrição da situação atual de trabalho compreendeu características relativas ao ambiente e aos equipamentos de trabalho, dando enfoque primordial, porém, às características relativas à organização do trabalho. Nas condições de trabalho foram abrangidas as condições físicas, químicas e biológicas. Foram obtidos dados sobre posto de trabalho: mobiliário, equipamentos, instrumentos, materiais etc. Com relação à organização do trabalho abordou-se: horário de trabalho, turnos, escalas, pausas, horas-extras, ritmo de trabalho, políticas de pessoal, tipo de vínculo, treinamento recebido etc. Buscou-se a compreensão das exigências físicas e mentais colocadas pelo trabalho.

Para este estudo, além da anamnese, foram analisados outros dados constantes dos prontuários de cada paciente (análise documental).

Foi feita uma análise temática das anamneses e prontuários. Tendo em vista o objetivo de caracterizar as situações de trabalho relacionadas aos distúrbios psíquicos apresentados pelos pacientes, e discutir a questão do estabelecimento do diagnóstico e do nexo causal com o trabalho, foram enfocados os seguintes temas: identificação, história de trabalho e relações com o desenvolvimento dos sinais e sintomas, quadro clínico e discussão do nexo causal com o trabalho, diagnóstico segundo a CID 10 , encaminhamento dado ao caso pela equipe de saúde mental.

Um resumo de cada caso é apresentado seguindo os temas acima citados. São inseridos depoimentos dos trabalhadores de forma a ilustrar algumas situações. Em relação ao diagnóstico, buscou-se caracterizar os casos de forma correspondente aos códigos da Classificação Internacional das Doenças - décima revisão (CID-10) (OMS, 1995). Após a apresentação dos casos analisados são descritos os aspectos que se destacam nos mesmos.

\section{Resultados}

\section{Caso 1}

Identificação: 46 anos, sexo masculino, natural da cidade de São Paulo, lo grau incompleto, casado, uma filha, casa própria e boas condições de vida.

História de trabalho e relações com o desenvolvimento dos sinais e sintomas: É motorista de empresas de transporte coletivo há 26 anos. Na empresa em que trabalha há 3 anos e 4 meses dirige ônibus dotado de motor dianteiro, estando exposto a ruído, calor e vibração; cumpre jornada das 15:40h à 00:50h, que se prolonga, com horas-extras freqüentes, até a 1h30min. Trabalha em trajeto de linha considerada violenta, tendo sofrido assalto à mão armada, por cinco vezes. Descreve a organização do trabalho nos seguintes termos: "A empresa pressiona muito e por qualquer coisa, demite sem direitos...Qualquer coisa é suspensão, advertência. Não há diálogo com a chefia. Eles querem é carro rodando na rua. Para ir ao médico, tem que pedir permissão. Se um colega bate o carro, "gancho". Querem só tirar o carro do local e o trabalhador é quem arca com a burocracia e descontam o prejuízo do seu salário".

Quadro clínico e discussão do nexo causal com o trabalho: O processo de adoecimento teve início após o último assalto. Nos dias seguintes ao assalto, trabalhou normalmente. Três dias após, em frente à garagem, presenciou um assassinato, prestando socorro à vítima. Sua fala ilustra esse processo: "Eu previ que ia ser assaltado. Meia-noite e quarenta, somente seis passageiros no ônibus... Ficaram apontando a arma e levaram dinheiro e passes. Por alguns segundos, fiquei sem saber o que fazer. Consegui dirigir até a garagem, tremendo. Fiquei duas ou três noites sem conseguir dormir, com suores intensos e as pernas tremendo. Não fiz ocorrência policial". Passou a apresentar sintomatologia na forma de tremores e ansiedade que, tendo se tornado incontrolável, levou-o a procurar médico e psicóloga da empresa, que não propuseram afastamento do trabalho.

Diagnóstico segundo a CID 10: Foi dado o diagnóstico de Síndrome Traumática Pós-As- 
salto (F43-1 Estado de Estresse Pós-Traumático, CID 10).

Encaminhamento dado ao caso pela equipe de saúde mental: O CRST-SÉ solicitou a emissão, pela empresa, da Comunicação de Acidente do Trabalho (CAT), o que não ocorreu. Foi então orientado o tratamento e emitido relatório à Previdência Social e CAT ex-officio, que foi reconhecida pelo órgão previdenciário, tendo o trabalhador recebido o auxílio-doença acidentário.

\section{Caso 2}

Identificação: 41 anos, sexo masculino, natural de Ilhéus, Bahia, há 20 anos em São Paulo, com lo grau completo, casado por duas vezes, 4 filhos, residindo em casa própria e com boas condições de vida.

História de trabalho e relações com o desenvolvimento dos sinais e sintomas: Foi encarregado de linha de produção por 10 anos em indústria de vidros, onde trabalhou por 16 anos. Sua atividade ocupacional compreendia o acompanhamento do processo das linhas de produção, tendo o quadro psíquico se manifestado após mudanças organizacionais na empresa, que automatizou o processo produtivo e demitiu trabalhadores, sobrecarregando-o, pois passou a ser encarregado de três linhas. Refere a existência de ritmo intenso, falta de autonomia, falta de reconhecimento em relação ao desempenho, a automação gerando desemprego e modificando o processo de trabalho sem a participação dos trabalhadores. "Falavam: 'Você não está vestindo a camisa da firma.... E eu sozinho, tocando as três linhas de produção, vendo os amigos sendo despedidos. Eram reuniões só para falar mal, nunca elogiavam. Diziam que iam pressionar até a pessoa não agüentar".

Quadro clínico e discussão do nexo causal com o trabalho: O processo de adoecimento iniciou-se por meio de sonhos com o serviço e alterações do sono. O paciente relatava sentirse "perturbado", tenso pela pressão por produção, aquém das suas possibilidades. Um dia, diante da paralisação de uma máquina, por defeito, o paciente apresentou crise hipertensiva, que tratou com anti-hipertensivos. Por conta própria, procurou também psiquiatra do convênio, que indicou psicoterapia e prescreveu medicação ansiolítica, mas não sugeriu afastamento do trabalho. Após quatro meses, o paciente foi demitido pela empresa, perdendo o direito ao seguimento terapêutico.

Diagnóstico segundo a CID 10: O CRST-SÉ elaborou relatório com diagnóstico de Síndrome de Fadiga (F48.0 - Neurastenia, CID 10).
Encaminhamento dado ao caso pela equipe de saúde mental: Não houve reconhecimento do relatório pela Previdência Social, que negou o fornecimento de auxílio-doença. O trabalhador recebeu o seguro-desemprego e acionou a empresa em processo de reintegração, sem resultado. Após a demissão o quadro de fadiga melhorou, encontrando-se o paciente atualmente em boas condições de saúde, mantendo o tratamento psicoterápico no CRST.

\section{Caso 3}

Identificação: 39 anos, sexo masculino, natural de São Paulo, 1o grau completo, solteiro, residindo com os pais em casa própria.

História de trabalho e relações com o desenvolvimento dos sinais e sintomas: Por 10 anos trabalhou como "dedetizador" em Serviço de Saúde Pública, estando exposto a organofosforados, carbamatos e raticidas.

Quadro clínico e discussão do nexo causal com o trabalho: Há dois anos, desenvolveu hipertensão arterial e distúrbio psíquico que se caracterizou por falta de apetite, insônia, tristeza, depressão, acompanhado de persecutoriedade, tremores de extremidades e recurso a etílicos "para acalmar". Este quadro levou-o à internação por período de 30 dias em hospital psiquiátrico, onde recebeu o diagnóstico de psicose. Somente durante o seguimento ambulatorial o psiquiatra da Unidade Básica de Saúde municipal relacionou o quadro clínico com a atividade ocupacional do paciente, encaminhando-o então ao CRST de Santo Amaro, onde foi realizada avaliação clínica, laboratorial e testes neuropsicológicos.

Diagnóstico segundo a CID 10: Foi dado o diagnóstico de Quadro Psicoorgânico Psicótico decorrente de exposição prolongada a Organofosforados (T-60.0 CID 10).

Encaminhamento dado ao caso pela equipe de saúde mental: $\mathrm{O}$ paciente procurou o CRSTSÉ para seguimento terapêutico, devido à falta de psiquiatra no outro serviço naquele momento. A empresa emitiu a CAT que, reconhecida pela Previdência Social, possibilitou ao trabalhador o recebimento do auxílio-doença acidentário. Faleceu em junho de 1998, com diagnóstico de infarto do miocárdio.

\section{Caso 4}

Identificação: 39 anos, sexo feminino, natural de Macéio, Alagoas, 2o grau incompleto, separada, dois filhos, residindo em casa própria com boas condições de vida.

História de trabalho e relações com o desenvolvimento dos sinais e sintomas: Trabalhou na 
atividade de agente operacional de empresa do ramo de transportes vendendo passagens por oito anos. Referiu: tensão por escalas aleatórias, falta de segurança, tendo sido vítima de assalto no posto de trabalho, rodízio entre estações, trabalho por turno e noturno, freqüentes horas-extras, trabalho repetitivo, ausência de promoção; posto de trabalho com guichês fechados, sem ventilação e com iluminação deficiente. Apresentou quadro clínico caracterizado por dor muscular intensa; ao procurar a chefia, foi readaptada na função de agente de segurança, sem afastamento do trabalho. Para a nova função, participou de treinamento envolvendo palestras no Instituto de Criminalística, necropsias no Instituto Médico Legal e visita à penitenciária.

Quadro clínico e discussão do nexo causal com o trabalho: Descreve o processo psíquico de adoecer a partir deste treinamento. Após 6 meses na função de agente de segurança, passou a apresentar perda de apetite e crises de choro, que procurava esconder, para não demonstrar fraqueza. Ao recusar-se a passar pelo treinamento em judô, foi orientada a procurar o ambulatório da empresa, que a encaminhou ao neurologista. Procurou o convênio da empresa. Por orientação do médico foi readaptada, permanecendo na área administrativa, onde descreve que "fazia servicinhos". Após um ano e meio obteve afastamento por 15 dias. Iniciou psicoterapia por conta própria, continuou na área administrativa e após um ano desenvolveu artrose, escoliose, alterações menstruais e depressão com tensão emocional. Ficou um ano e meio afastada do trabalho recebendo auxílio-doença previdenciário e realizando tratamento clínico, fisioterápico e psicoterápico, após o que solicitou alta ao INSS (Instituto Nacional de Seguro Social). Relata que ao retornar à empresa foi "encostada" no setor de contabilidade, tendo enfrentado preconceito por parte dos colegas, sentimentos de perseguição e de vazio e desesperança. Começou a sentir dores de cabeça intensas, procurou psiquiatra e foi afastada do trabalho por mais um ano e meio, recebendo o auxílio-doença previdenciário.

Diagnóstico segundo a CID 10: Recebeu o diagnóstico de F43.1, que evoluiu para F43.2 Estado de Estresse Pós-Traumático e Transtornos de Adaptação. $\mathrm{O}$ assalto representou o trauma, que foi agravado pela readaptação para a função de agente de segurança. Codificouse como F43.2 (CID 10) - Distúrbios da Adaptação pois, após sofrer assalto como agente operacional, a trabalhadora foi readaptada para a função de agente de segurança e, depois de afastamento psiquiátrico, viu-se "encostada" no setor de contabilidade e passou a apresentar diferentes sintomatologias, com quadros depressivos e repetida alternância de reafastamento/retorno ao trabalho.

Encaminhamento dado ao caso pela equipe de saúde mental: O CRST-SÉ emitiu relatório que foi encaminhado ao INSS, que não reconheceu o quadro como doença do trabalho. Obteve auxílio-doença previdenciário. Em tratamento psicoterápico.

\section{Caso 5}

Identificação : 34 anos, sexo masculino, natural de São Paulo, 2o grau completo em contabilidade, casado, dois filhos, residindo em moradia própria, com boas condições de vida.

História de trabalho e relações com o desenvolvimento dos sinais e sintomas: Por nove anos trabalhou em banco privado. Quando trabalhava na compensação de cheques, desenvolveu quadro clínico de LER/DORT. Em março 1993, sofreu cirurgia de tendinite e cisto sinovial, permanecendo afastado do trabalho por seis meses, recebendo auxílio-doença previdenciário, pois a CAT emitida pela empresa não fora reconhecida pelo INSS. Ao retornar ao trabalho foi transferido, à sua revelia, para Agência Bancária, na função de caixa, sem uma readaptação adequada. A agência era distante de sua residência, o deslocamento consumindo-lhe quatro horas por dia. A chefia da agência pressionava-o para atendimento rápido aos clientes. Referiu como fontes de grande tensão: transferência para outra agência sem consulta prévia, pressões intensas por parte da gerência, medo da perda do emprego em razão do processo de fechamento de agências. "Na agência a chefia era exigente e reclamava de que eu era muito bonzinho, perdendo tempo com os clientes. Para chegar a esta agência eu levava duas horas da residência. Entrava às 10:00 e saía às 16:15 e nos dias de pico às 19:00, com 15 minutos de almoço".

Quadro clínico e discussão do nexo causal com o trabalho: Após um ano e quatro meses como caixa, apresentou quadro clínico de gastrite e depressão, diagnosticados pelo médico do convênio. Em agosto de 1995, compareceu ao trabalho pela última vez, pois sentia-se perseguido e com "medo de tudo", tendo sido demitido, em outubro, por abandono de emprego. Sua fala ilustra este ponto: "Comecei a sentir medo de tudo, muita cobrança no serviço, saía de lá com o pescoço duro e não conseguia dormir. Procurei o médico do convênio, fiz até tomografia. Com medo exagerado de tudo, comecei a não atender mais ninguém. Não conseguia 
ir ao banco. Parecia que alguém estava me vigiando, qualquer coisa me assustava, o sono era agitado e fiquei muito agressivo com meu filho mais velho". Em novembro, a mãe do paciente procurou o CRST, pois o filho estava em casa "parado", isolado, sem atender nem aos telefonemas. A mãe foi orientada a procurar emergência psiquiátrica do serviço público, que prescreveu antidepressivo ao paciente.

Diagnóstico segundo a CID 10: Foi dado diagnóstico de Síndrome Depressiva Paranóide (F43.2 - Transtornos de Adaptação).

Encaminhamento dado ao caso pela equipe de saúde mental: $\mathrm{O}$ paciente foi encaminhado ao INSS com relatório, tendo recebido auxíliodoença previdenciário até dezembro de 1996.

\section{Caso 6}

Identificação: 37 anos, sexo masculino, natural de Ouro Preto, Minas Gerais, 1o grau completo, separado, uma filha com quem reside, em quarto alugado, em condições insatisfatórias.

História de trabalho e relações com o desenvolvimento dos sinais e sintomas: Por 21 anos trabalhou como motorista em empresas de transporte coletivo urbano.

Quadro clínico e discussão do nexo causal com o trabalho: Seu processo de adoecimento iniciou-se há dois anos, após acidente de trânsito ocorrido durante o período de trabalho, em que atropelou um pedestre devido a defeitos mecânicos no veículo. No acidente fez traumatismo crâneo-encefálico, tendo sido removido para hospital-escola, de onde foi transferido para emergência psiquiátrica e de lá para hospital psiquiátrico conveniado com a empresa, onde permaneceu internado por 30 dias. Retornou ao trabalho, readaptado para a função de abastecimento de veículos. Após uma semana na função, sem orientação terapêutica, o quadro agravou-se, levando-o a reinternação por quatro meses. Retornou ao trabalho e foi demitido. $\mathrm{O}$ acidente não foi comunicado pela empresa, e a CAT emitida pelo sindicato não foi reconhecida pelo INSS.

Diagnóstico segundo a CID 10: Recebeu o diagnóstico de S06.9 - Traumatismo Intracraneano e F09 - Psicose Orgânica.

Encaminhamento dado ao caso pela equipe de saúde mental: Encaminhado ao INSS, desde 1995 recebe do INSS auxílio-doença previdenciário, que tenta transformar em auxílio-acidentário, mediante processo em trâmite junto à Justiça do Trabalho.

\section{Caso 7}

Identificação: Sexo masculino, 43 anos, casado, natural de São Paulo, nível superior incompleto.

História de trabalho e relações com o desenvolvimento dos sinais e sintomas: Trabalhou por 20 anos em um banco privado, tendo iniciado como auxiliar de seção (crédito de liquidação) e terminado como gerente de produção, cargo este exercido por quatro anos. Morava a 43 quilometros de distância da empresa. Cuidava de 600 contas ativas de pessoas físicas. Suas principais atribuições eram: decidir quais cheques de clientes com contas estouradas pagar e quais devolver dentre 300 a 400 casos por dia; ligar para os clientes avisando; visitar clientes; analisar dados de clientes para decidir sobre empréstimo; cadastrar clientes. Aponta os seguintes problemas: excesso de trabalho, levando a jornadas superiores a 12 horas/dia e a continuar trabalhando em casa; problemas com clientes devido à porta giratória; metas irreais e sempre crescentes a cumprir (novas contas, venda de cartões, venda de seguro); falta de retaguarda, obrigando a pedir documentos, digitar dados no computador, dar telefonemas, levar malotes; assalto ocorrido em 03/97.

Quadro clínico e Discussão do nexo causal com o trabalho: Teve uma crise hipertensiva três anos antes. Passou a apresentar cansaço, "moleza", mal-estar, palidez. Tinha crises de choro quando aconteciam problemas por causa da porta giratória. Após o assalto teve dez dias de licença, mas voltou ao trabalho três dias antes, porque o Banco precisava dele. Ficou nervoso, "abalado", "um trapo em pé", com hipertensão arterial sistêmica, cefaléia. Chegou a deixar crescer barba e bigode para não ser reconhecido pelos bandidos.

Diagnóstico segundo a CID 10: O diagnóstico dado foi de transtorno de estresse pós-traumático (F43.1), reação ao estresse grave (F43.8) e reação depressiva (F32).

Encaminhamento dado ao caso pela equipe de saúde mental: Foi elaborado relatório e comunicação de acidente de trabalho e encaminhado ao INSS, que reconheceu a CAT.

\section{Principais Características dos Casos}

A Tabela 1 mostra a distribuição dos casos quanto a sexo, estado civil, escolaridade, idade, naturalidade, ramo de atividade e último cargo. Verifica-se a existência de apenas uma mulher. Tivemos quatro casados, dois separados e um solteiro. O nível de escolaridade apresentou-se heterogêneo, variando de forma corres- 
pondente às exigências educacionais da função, de lo grau incompleto a superior incompleto. Quanto à idade, variou de 34 a 46 anos, com idade média de 39,8. A naturalidade mais comum foi São Paulo. Tivemos dois trabalhadores de empresas de ônibus, um do metrô, um de indústria de vidros, dois de bancos e um de serviço de saúde pública. Em relação aos cargos tivemos dois motoristas, um encarregado, um gerente, um dedetizador, um agente de segurança e um caixa.

As situações de trabalho relatadas caracterizam-se por: condições de trabalho nocivas (por exemplo, ruído, calor, vibração, principalmente no caso 1; produtos químicos, no caso 2); problemas relacionados à organização do trabalho (por exemplo, jornadas extensas e horas-extras, no caso 1 e 7; excesso de trabalho e pressão por produção, principalmente nos casos 2 e 7; metas irreais e falta de retaguarda no caso 7); gestão inadequada (nos casos 4 e 5 ocorreu um remanejamento para função inadequada às características de personalidade; no caso 5 , além desse remanejamento, o trabalhador foi transferido para uma agência muito distante de sua moradia; nos casos 1, 4, 6 e 7 não houve um procedimento adequado em relação ao trauma sofrido pelo trabalhador, i.e., assalto e acidente); violência (por exemplo: assaltos).

Os quadros clínicos mostraram a existência de sinais e sintomas ligados a sentimentos (por exemplo, medo, ansiedade, depressão, nervosismo, tensão), fadiga, mal-estar, perda de apetite, distúrbios de sono, distúrbios psicossomáticos (gastrite, crises hipertensivas), além disso, principalmente nos casos 2, 5 e 7 ocorreu contaminação involuntária do tempo de lazer, ou seja, os trabalhadores sonhavam com o trabalho, não conseguiam "desligar-se".

Os diagnósticos foram variados. Em três casos $(1,4,7)$ tivemos síndromes pós-traumáticas ligadas a assaltos. Dois casos referem-se a quadros psicóticos orgânicos ligados a acidentes ou exposição a produtos químicos $(3,6)$. Apareceram ainda quadros de fadiga (caso 2), depressivos (casos 5 e 7), paranóides (caso 5), de adaptação (caso 4) e de reação ao estresse grave (caso 7). Em todos os casos, é possível relacionar o quadro clínico com a situação de trabalho.

\section{Discussão}

Com relação à situação de trabalho podemos notar a existência de condições de trabalho físicas, químicas ou biológicas que podem cau- sar danos à saúde física e/ou mental. Tais condições de trabalho podem ocorrer concomitantemente a problemas relacionados à organização do trabalho e às condições de vida. Portanto, uma série de aspectos da situação de trabalho e extra trabalho podem atuar de forma conjunta no desencadeamento de transtornos mentais. É importante observar como estes vários aspectos se inter-relacionam.

O papel de destaque representado pela organização do trabalho está de acordo com as propostas de psicodinâmica do trabalho (Dejours et al., 1994) e das teorias de estresse (Karasek \& Theorell, 1990). De maneira geral, pode-se afirmar que quanto menor a autonomia do trabalhador na organização da sua atividade, maiores as possibilidades de que a atividade gere transtornos à saúde mental. Novas formas de organização do trabalho, novas tecnologias e a precarização do trabalho trazem o temor do desemprego e a intensificação do trabalho. Percebe-se que o excesso de trabalho e a pressão por produção ocorrem em todos os degraus da hierarquia. Encarregados e gerentes vivem tais situações assim como operários e bancários.

Há que se destacar, ainda, a crescente importância da violência urbana como um dos aspectos de caráter social a afetar as mais variadas situações de trabalho. Tal fenômeno vem adquirindo contornos alarmantes ao longo dos últimos anos, atingindo com freqüência o cotidiano de bilheteiros, motoristas, cobradores, vigilantes e bancários, por exemplo. Apesar disso, aparentemente tal problemática não tem sido alvo de uma atenção específica por parte das empresas. Outra face da violência sobre o cotidiano dos trabalhadores caracterizase pelos acidentes de trânsito, como ocorrido no caso 6 , com repercussões sobre a saúde mental do trabalhador.

No que concerne ao diagnóstico, uma dificuldade importante reside na vinculação entre os quadros clínicos e o trabalho, tal como apontado por Seligmann-Silva (1995:289), que afirma: " não existe um consenso que tenha permitido uma classificação dos distúrbios psíquicos vinculados ao trabalho, existe uma concordância da importância etiológica do trabalho, mas não a respeito do modo como se exerce a conexão trabalho/psiquismo de forma suficiente a permitir um quadro teórico. Os distintos modelos teóricos vêm trazendo dificuldades para a clínica e prevenção".

Outra dificuldade importante refere-se à ausência, na Classificação Internacional das Doenças, de um grupo de diagnósticos de distúrbios psíquicos relacionados com o trabalho. 
Neste sentido, pode-se incluir o diagnóstico da patologia e adicionar o Z-56 para referir que o problema está relacionado com o emprego e/ou desemprego.

Após analisar as descrições clínicas e diretrizes para diagnóstico constantes da Classificação Internacional das Doenças, SeligmannSilva (1995) ponderou que os títulos Transtornos neuróticos, Transtornos relacionados ao estresse e Transtornos somatoformes (F40 F48, Capítulo V da CID 10) são os que reúnem a maior parte dos diagnósticos em que a dimensão psicossocial do trabalho pode assumir relevância fundamental. A autora aponta, ainda, as seguintes síndromes neuróticas como as que com freqüência apresentam relação com o trabalho: síndrome do esgotamento profissional (estafa ou burn-out); síndrome da fadiga crônica (fadiga patológica, fadiga industrial); síndromes pós-traumáticas; síndromes depressivas e paranóides.

Dentre as Síndromes Neuróticas descritas por Seligmann-Silva, nos casos analisados foram identificados os de fadiga crônica, síndrome pós-traumáticas, síndromes depressivas e paranóides.

A Síndrome da Fadiga Crônica corresponde à fadiga acumulada ao longo de períodos de duração variável, diante de uma situação de trabalho que não permite recuperação suficiente por intermédio de sono e repouso. A característica principal é a fadiga constante, física e mental, acompanhada de distúrbios de sono, cansaço, irritabilidade e desânimo.

Voge (1985) descreve a neurose traumática como quadro imediato de irritabilidade, angústia difusa, reações emocionais exageradas. Além disso, o indivíduo revê e revive mentalmente a cena traumática, acompanhado de mal-estar, às vezes com sudorese e taquicardia. Os pesadelos também repetem o evento traumático com distúrbios do sono, irritabilidade e um estado de tensão no qual ocorrem sobressaltos, como se a pessoa estivesse em permanente estado de prontidão.

A Sindrome Paranóide descrita por Seligmann-Silva (1995) como quadros do tipo neurótico em que se desenvolvem fortes sentimentos de insegurança, com vivências de ameaça em situação na qual sejam identificados aspectos e pressões de tipo potencialmente persecutório, com dispositivos rígidos de controle. Quanto maiores forem as barreiras à comunicação e maior o isolamento do assalariado, maior a facilidade de que se desenvolvam essas manifestações. Tais manifestações de ansiedade de teor persecutório podem intensificar-se a ponto de perturbar seriamente os rela- cionamentos interpessoais e o desempenho. Paralelamente, podem surgir graus de irritabilidade e também, com freqüência, distúrbios do sono.

Seligmann-Silva (1995) descreve que as síndromes depressivas podem ter sua patogenia, desencadeamento e evolução nitidamente associados às vivências do trabalho, podendo a depressão manifestar-se em quadros agudos ou crônicos típicos (tristeza, vivências de perda ou fracasso e falta de esperança). No entanto, os quadros depressivos associados ao trabalho muitas vezes não são típicos; revelam-se de forma mais sutil, apresentando como principal manifestação o desânimo diante da vida e do futuro.

Outros quadros identificados neste estudo que estão relacionados com a situação de trabalho foram: quadros de distúrbios psicossomáticos, como crise hipertensiva e gastrite e transtornos orgânicos de personalidade ou psicose orgânicas.

Como já afirmamos anteriormente, o nexo entre adoecimento e situação de trabalho não é simples, uma vez que tal processo é específico para cada indivíduo, envolvendo sua história de vida e de trabalho. Para estabelecer o nexo, torna-se fundamental a descrição detalhada da situação de trabalho, quanto ao ambiente, à organização e à percepção da influência do trabalho no processo de adoecer.

A Comunicação do Acidente do Trabalho deve ser emitida sempre que o diagnóstico evidencie o papel da situação de trabalho como desencadeante ou agravante do adoecimento, e mesmo diante da suspeita de tal nexo etiológico, conforme Resolução no 1488/98 do Conselho Federal de Medicina (CFM, 1998).

Por meio do presente estudo foi possível verificar que para a maioria dos casos analisados não houve emissão da CAT pelas empresas empregadoras, tendo então o CSRT emitido a CAT ex-officio e requerido à Previdência Social a transformação do auxílio-doença previdenciário em acidentário.

A evolução dos quadros clínicos mantém estreita associação com o suporte fornecido (ou não) pelos serviços de saúde, pela empresa, sindicato, familiares e instituições, entendendo-se tal suporte como um conjunto de ações que resgatem a identidade profissional e social dos trabalhadores.

No que se refere à evolução dos quadros clínicos, convém atentar para os casos de afastamento do trabalho com retorno à mesma situação de trabalho ou para os casos de mudanças de função sem o respaldo de uma adequada política de readaptação que resultaram na pio- 
ra da sintomatologia. É importante avaliar cuidadosamente o retorno ao trabalho após afastamentos por distúrbios psíquicos, sendo necessárias ações integradas e acompanhamento multidisciplinar, abrangendo o tratamento com medicação, psicoterapia e suporte por parte dos colegas e das chefias.

A problemática da demissão atingiu a maioria dos casos estudados, alguns tendo sido demitidos com o quadro clínico em atividade. A demissão representa a exclusão dos trabalhadores, funcionando a situação de trabalho (com organizações rígidas, pressão do tempo e das gerências etc.), como selecionadora de trabalhadores. Além de gerarem a perda do direito à assistência por parte do convênio, as demissões levam à perda da identidade profissional $\mathrm{e}$

\section{Agradecimentos}

Agradecemos a colaboração da Profa. Edith SeligmannSilva pela orientação e leitura cuidadosa deste artigo.

\section{Referências}

CFM (Conselho Federal de Medicina), 1998. Resolução CFM № 1488/98, de 11/02/1998. Brasília: CFM.

DAÚD Jr., N., 1997. Saúde mental e trabalho para uma ação estratégica em saúde mental do trabalhador. In: Saúde, Meio Ambiente e Condições de Trabalho: Conteúdos Básicos para uma Ação Sindical (R. Todeschini, org.), pp. 177-206, São Paulo: Central Única dos Trabalhadores/Fundacentro.

DEJOURS, C., 1986. Por um novo conceito de saúde. Revista Brasileira de Saúde Ocupacional, 14:7-11.

DEJOURS, C.; ABDOUCHELI, E.; JAYET, C. \& BETIOL, M. I. S., 1994. Psicodinâmica do Trabalho: Contribuição da Escola Dejouriana à Análise da Relação Prazer, Sofrimento e Trabalho. São Paulo: Atlas.

FRANKENHAEUSER, M. \& GARDELL, B., 1976. Underload and overload in working life: Outline of a multidisciplinary approach. Journal of Human Stress, 2:35-46.

KALIMO, R., 1980. Stress in work: Conceptual analysis and a study on prison personnel. Scandinavian Journal of Work, Environment \& Health, 6(Sup. 3):1-148.

KARASEK, R. A. \& THEORELL, T., 1990. Healthy Work. New York: Basic Books. à piora da qualidade de vida, com a diminuição dos recursos financeiros.

Considerando as dificuldades de estabelecer o nexo com o trabalho e o diagnóstico dos distúrbios psíquicos é fundamental: capacitar os profissionais dos serviços de saúde para que considerem a importância da situação de trabalho como um dos determinantes no processo saúde/doença; reestruturar os sistemas de informações em saúde, envolvendo um sistema de vigilância epidemiológica com notificação dos casos com suspeita de relação com o trabalho, independentemente da caracterização por parte da Previdência Social; e desenvolver ações interinstitucionais e multidisciplinares em Saúde Mental e Trabalho.
LEVI, L., 1988. Definiciones y aspectos teóricos de la salud en relación con el trabajo. In: Los Factores Psicosociales en el Trabajo y su Relacion con la Salud (R. Kalimo, M. A. El Batawi \& C. L. Cooper, ed.), pp. 9-14, Geneva: Organización Mundial de la Salud.

MINAYO, M. C. S.,1993. O Desafio do Conhecimento: Pesquisa Qualitativa em Saúde. 2a Ed. São Paulo: Editora Hucitec/Rio de Janeiro: ABRASCO.

MPAS (Ministério da Previdência e Assistência Social), 1999. Decreto № 3048/99, de 06 de maio de 1999. Brasília, DF: Diário Oficial da União, no 89, 12 mai. SELIGMANN-SILVA, E., 1994. Desgaste Mental no Trabalho Dominado. Rio de Janeiro: Editora UFRJ/ Editora Cortez.

SELIGMANN-SILVA, E., 1995. Psicopatologia e psicodinâmica no trabalho. In: Patologia do Trabalho (R. Mendes, ed.), pp. 287-310, Rio de Janeiro: Ed. Atheneu.

VOGE, C., 1985. Problèmes médicaux et médico-légaux posés par les agressions à main armée dans les établissements bancaires. In: A Psychopathologie du Travail (C. Dejours, C. Veil \& Wisner, ed.), pp. 87-94, Paris: Enterprise Moderne d'Editions/ Editions ESF 